\title{
Screening for Ovarian Cancer: Recommendation Statement
}

\section{U.S. Preventive Services Task Force}

Members of the U.S. Preventive Services Task Force* are Ned Calonge, MD, MPH, Chair, USPSTF (Acting Chief Medical Officer, Colorado Department of Public Health and Environment, Denver, Colo); Janet D. Allan PbD, RN, CS, Vice-chair, USPSTF (Dean, School of Nursing, University of Maryland Baltimore, Baltimore, Md); Alfred O. Berg, MD, MPH (Professor and Chair, Department of Family Medicine, University of Washington Seattle, Wasb); Paul S. Frame, MD (Tri-County Family Medicine, Cobocton, NY, and Clinical Professor of Family Medicine, University of Rochester, Rochester, NY); Joxel Garcia, MD, MBA (Deputy Director, Pan American Health Organization, Washington, DC), Leon Gordis, MD, DrPH (Professor, Epidemiology Department, Johns Hopkins Bloomberg School of Public Health, Baltimore, Md), Kimberly D. Gregory, MD, MPH (Director,

Women's Health Research and Maternal-Fetal Medicine, Department of Obstetrics and Gynecology, Cedars-Sinai Medical Center, Los Angeles, Califf; Russell Harris, MD, MPH (Associate Professor of Medicine, Sheps Center for Health Services Research, University of North Carolina School of Medicine, Chapel Hill, NC); Mark S. Johnson, MD, MPH (Professor of Family Medicine, University of Medicine and Dentistry of New Jersey-New Jersey Medical School, Newark, NJ); Jonatban D. Klein, MD, MPH (Associate Professor, Department of Pediatrics, University of Rochester School of Medicine, Rochester, NY); Carol Loveland-Cherry, PhD, RN (Executive Associate Dean, School of Nursing, University of Michigan, Ann Arbor, Micb), Virginia A. Moyer, MD, MPH (Professor, Department of Pediatrics, University of Texas at Houston, Houston, Tex), Judith K. Ockene, PbD (Professor of Medicine and Chief Division of Preventive and Behavioral Medicine, University of Massacbusetts Medical School, Worcester, Mass); Diana B. Petitti, MD, MPH (Director, Research and Evaluation, Kaiser Permanente Southern California, Pasadena, Calif), Albert L. Siu, MD, MSPH (Professor and Chairman Brookdale Department of Geriatrics and Adult Development, Mount Sinai Medical Center, New York, NY); Steven M. Teutscb, MD, MPH (Executive Director, Outcomes Research and Management, Merck \& Company, Inc, West Point, $\mathrm{Pa}$ ), and Barbara P. Yawn, MD, MSc (Director of Research, Olmstead Research Center, Rochester, Minn).

\section{CORRESPONDING AUTHOR}

Ned Calonge, MD, MPH

Chair, U.S. Preventive Services Task Force c/o Program Director, USPSTF

Agency for Healthcare Research and Quality 540 Gaither Road

Rockville, MD 20850

uspstf@ahrq.gov.

* Members of the Task Force at the time this recommendation was finalized. For a list of current Task Force members, go to http: //www.ahrq.gov/clinic/uspstfab.htm.
Ann Fam Med 2004;2:260-262. DOI: 10.1370/afm.200.

$\mathrm{T}$ his statement summarizes the current U.S. Preventive Services Task Force (USPSTF) recommendation on screening for ovarian cancer and the supporting evidence, and updates the 1996 recommendations contained in the Guide to Clinical Preventive Services, Second Edition: Periodic Updates. ${ }^{1}$ In 1996, the USPSTF recommended against routine screening for ovarian cancer (a " $\mathrm{D}$ " recommendation). Explanations of the ratings and of the strength of overall evidence are given in Appendix A and in Appendix $B$, respectively. The complete information on which this statement is based, including evidence tables and references, is available in the brief evidence update "Screening for Ovarian Cancer,"2 available through the USPSTF Web site at http://www.preventiveservices.ahrq.gov and through the National Guideline Clearinghouse ${ }^{\mathrm{TM}}$ (http://www.guideline.gov). The recommendation statement and brief evidence updates are also available from the Agency for Healthcare Research and Quality (AHRQ) Publications Clearinghouse in print through subscription to the Guide to Clinical Preventive Services, Third Edition: Periodic Updates.

\section{RECOMMENDATION}

The U.S. Preventive Services Task Force (USPSTF) recommends against routine screening for ovarian cancer. D recommendation.

The USPSTF found fair evidence that screening with serum CA-125 level or transvaginal ultrasound can detect ovarian cancer at an earlier stage than it can be detected in the absence of screening, bowever, the USPSTF found fair evidence that earlier detection would likely bave a small effect, at best, on mortality from ovarian cancer. Because of the low prevalence of ovarian cancer and the invasive nature of diagnostic testing after a positive screening test, there is fair evidence that screening could likely lead to important barms. The USPSTF concluded that the potential barms outweigh the potential benefits.

\section{CLINICAL CONSIDERATIONS}

- There is no existing evidence that any screening test, including CA-125, ultrasound, or pelvic examination, reduces mortality from ovarian cancer. Furthermore, existing evidence that screening can detect early-stage ovarian cancer is insufficient to indicate that this earlier diagnosis will reduce mortality.

- Because there is a low incidence of ovarian cancer in the general population (age-adjusted incidence of 17 per 100,000 women), screening for ovarian cancer is likely to have a relatively low yield. The great majority of women with a positive screening test will not have ovarian cancer (ie, they will have a false-positive result). In women at average risk, the positive predictive value of an abnormal screening test is, at best, approximately $2 \%$ (ie, $98 \%$ of women with positive test results will not have ovarian cancer).

- The positive predictive value of an initially positive screening test would be more favorable for women at higher risk. For example, the lifetime 
probability of ovarian cancer increases from about $1.6 \%$ in a 35 -year-old woman without a family history of ovarian cancer to about $5 \%$ if she has one relative and $7 \%$ if she has two relatives with ovarian cancer. If ongoing clinical trials show that screening has a beneficial effect on mortality rates, then women at higher risk are likely to experience the greatest benefit.

\section{DISCUSSION}

Ovarian cancer is the fifth leading cause of cancer death among women in the U.S., accounting for an estimated 25,400 new cases and 14,300 deaths in 2003. ${ }^{3}$ Several risk factors are associated with ovarian cancer. Family history increases the risk for ovarian cancer: having 1 first- or second-degree relative with ovarian cancer increases risk by about threefold. ${ }^{4}$ Carriers of the BRCA1 or BRCA2 gene mutations are also at increased risk. ${ }^{5}$ The risk for developing ovarian cancer is reduced with oral contraceptive use and pregnancy of any duration. ${ }^{6}$ Some studies have shown that postmenopausal women taking estrogen may be at increased risk for developing ovarian cancer. ${ }^{7,8}$

Most women with ovarian cancer have non-localized disease at the time of diagnosis. ${ }^{3}$ A randomized controlled trial (RCT) using multi-modal screening (CA-125 screening, followed by ultrasound for abnormally elevated levels) reported that $50 \%$ of patients with ovarian cancer in the screened group were in Stage I, compared with only 5\% in the control group. ${ }^{2,9}$ This difference was not statistically significant. Two large cohort studies using transvaginal ultrasound screening reported that $59 \%$ to $65 \%$ of ovarian cancers were diagnosed in Stage I. ${ }^{10,11}$ However, there is no evidence that detecting earlier-stage tumors through screening leads to a decrease in ovarian cancer-specific mortality.

Establishing the true sensitivity of CA-125 or ultrasound is limited by several factors. The studies assessing the accuracy of screening tests have used different thresholds to define an elevated CA-125, different lengths of clinical follow-up, and have included small numbers of patients. In women at average risk for ovarian cancer, using thresholds of $30 \mathrm{U} / \mathrm{mL}$ or $35 \mathrm{U} / \mathrm{mL}$, the 1 -year follow-up sensitivity of CA-125 screening, followed by ultrasound, has been reported to be about $80 \%$; the specificity is nearly $100 \% .{ }^{12-14}$ However, using a similar CA-125 threshold for women at high risk for ovarian cancer, the sensitivity would be reduced to $50 \%$. The estimated sensitivity of annual transvaginal ultrasound at 1 -year follow-up is $88 \%$ (95\% Confidence Interval $[\mathrm{CI}], 47 \%-100 \%)$; and the specificity is estimated to range from $97 \%$ to $99 \% .{ }^{15}$ There is conflicting evidence as to whether adding color Doppler imaging to ultrasound screening can reduce the rate of false-positive test results. ${ }^{16,17}$ There are few data to determine the sensitivity and specificity of successive rounds of screening.

There is a significant potential for harms associated with screening for ovarian cancer, although there are few data to assess the magnitude of harms from screening, such as needless surgery or increased anxiety. A study by the British Health Technology Assessment program (HTA) estimated that screening a hypothetical cohort of 10,000 women aged 50 to 64 for ovarian cancer, using either annual CA-125 or twice-yearly transvaginal ultrasound (assuming specificities of $97 \%$ and $93 \%$, respectively), would result in 300 women (using CA-125) or 350 women (using ultrasound) who do not have ovarian cancer being recalled each year for further assessment, resulting in potential distress and anxiety in otherwise healthy women. ${ }^{15}$ Of these, 20 (using CA125 ) or 65 (using ultrasound) women without ovarian cancer would undergo surgery each year. For women at average risk for ovarian cancer, the positive predictive value of an abnormal screening test is, at best, approximately $2 \%$. On the other hand, the potential benefits of screening (based on this model's optimistic assumption that earlier treatment leads to a $40 \%$ mortality reduction) would yield a maximum of 4 additional cancers detected per year, and would result in 1.5 additional 5-year survivors for each year of screening.

Although no RCT of screening for ovarian cancer with mortality outcomes in the general population has yet been completed, at least 3 such RCTs are currently in progress: the UK Collaborative Trial of Ovarian Cancer Screening; the NIH Prostate, Lung, Colorectal and Ovarian (PLCO) Cancer Screening Trial; and the European Randomized Trial of Ovarian Cancer Screening. ${ }^{18-20}$

\section{RECOMMENDATIONS OF OTHERS}

Routine screening for ovarian cancer is not recommended by any medical organization. The American Cancer Society (ACS) states that women with a strong family history of this disease may be screened, but transvaginal ultrasound and CA-125 are not recommended for screening women without known strong risk factors for ovarian cancer. ${ }^{21}$ Instead of routine screening, the American College of Obstetricians and Gynecologists (ACOG) suggests that generalist obstetrician-gynecologists remain vigilant for the early signs and symptoms of ovarian cancer, such as abdominal or pelvic pain and unexplained weight loss, and that these symptoms be evaluated by pelvic examination, CA-125, or ultrasound. ${ }^{22}$ The Canadian Task Force on Preventive Health Care (CTFPHC), recommended against screening asymptomatic pre- and post-menopausal women in $1994 .{ }^{23}$ The Canadian Task Force also found insufficient evidence to recommend for or against screening high-risk women with a family 


\section{APPENDIX A}

\section{U.S. Preventive Services Task Force Recommendations and Ratings}

The Task Force grades its recommendations according to one of 5 classifications (A, B, C, D, I) reflecting the strength of evidence and magnitude of net benefit (benefits minus harms):

A. The USPSTF strongly recommends that clinicians provide [the service] to eligible patients. The USPSTF found good evidence that [the service] improves important health outcomes and concludes that benefits substantially outweigh harms.

B. The USPSTF recommends that clinicians provide [the service] to eligible patients. The USPSTF found at least fair evidence that [the service] improves important health outcomes and concludes that benefits outweigh harms.

c. The USPSTF makes no recommendation for or against routine provision of [the service]. The USPSTF found at least fair evidence that [the service] can improve health outcomes but concludes that the balance of benefits and harms is too close to justify a general recommendation.

D. The USPSTF recommends against routinely providing [the service] to asymptomatic patients. The USPSTF found at least fair evidence that [the service] is ineffective or that harms outweigh benefits.

I. The USPSTF concludes that the evidence is insufficient to recommend for or against routinely providing [the service]. Evidence that [the service] is effective is lacking, of poor quality, or conflicting, and the balance of benefits and harms cannot be determined.

\section{APPENDIX B}

\section{U.S. Preventive Services Task Force Strength of Overall Evidence}

The USPSTF grades the quality of the overall evidence for a service on a 3-point scale (good, fair, poor):

Good

Evidence includes consistent results from well-designed, well-conducted studies in representative populations that directly assess effects on health outcomes.

Fair

Evidence is sufficient to determine effects on health outcomes, but the strength of the evidence is limited by the number, quality, or consistency of the individual studies, generalizability to routine practice, or indirect nature of the evidence on health outcomes.

\section{Poor}

Evidence is insufficient to assess the effects on health outcomes because of limited number or power of studies, important flaws in their design or conduct, gaps in the chain of evidence, or lack of information on important health outcomes.

history of ovarian cancer, but noted that expert opinion suggested these women be referred to an academic health center for regular combination screening.

To read or post commentaries in response to this article, see it online at http://www.annfammed.org/cgi/content/full/2/3/260.

Key words: Ovarian neoplasms; mass screening; practice guidelines

Disclaimer: Recommendations made by the USPSTF are independent of the U.S. Government. They should not be construed as an official position of AHRQ or the U.S. Department of Health and Human Services.

\section{References}

1. U.S. Preventive Services Task Force. Guide to Clinical Preventive Services. 2nd ed. Washington, DC: Office of Disease Prevention and Health Promotion; 1996.
2. Nelson HD, Westhoff C, Piepert J, Berg A. Screening for Ovarian Cancer: Brief Evidence Update, May 25, 2004. Available at: http: //www.ahrq.gov/clinic/uspstf/uspstopics.htm.

3. American Cancer Society. Cancer Facts \& Figures 2003. Available at: http://www.cancer.org/downloads/STT/CAFF2003PW/Secured.pdf. Accessed April 2, 2003.

4. Kerlikowske K, Brown JS, Grady DG. Should women with familial ovarian cancer undergo prophylactic oophorectomy? Obstet Gynecol. 1992:80:700-707

5. Ford D, Easton DF. The genetics of breast and ovarian cancer. $\mathrm{Br} J$ Cancer. 1995; 72:805-812

6. Whittemore AS, Harris R, Itnyre J. Characteristics relating to ovarian cancer risk: collaborative analysis of 12 US case-control studies. II. Invasive epithelial ovarian cancers in white women. Collaborative Ovarian Cancer Group. Am J Epidemiol. 1992;136:1184-1203.

7.Lacey JV Jr, Mink PJ, Lubin JH, et al. Menopausal hormone replacement therapy and risk of ovarian cancer. JAMA. 2002;288:334-341.

8. Rodriguez C, Patel A, Calle E, Jacob E, Thun M. Estrogen replacement therapy and ovarian cancer mortality in a large prospective study of US women. JAMA. 2001;285:1460-1465.

9. Jacobs IJ, Skates SJ, MacDonald N, et al. Screening for ovarian cancer: a pilot randomised controlled trial. Lancet. 1999;353:1207-1210.

10. Sato S, Yokoyama Y, Sakamoto T, Futagami M, Saito Y. Usefulness of mass screening for ovarian carcinoma using transvaginal ultrasonography. Cancer. 2000;89:582-588.

11. van Nagell JR Jr, DePriest PD, Reedy MB, et al. The efficacy of transvaginal sonographic screening in asymptomatic women at risk for ovarian cancer. Gynecol Oncol. 2000;77:350-356.

12. Jacobs I, Stabile I, Bridges J, et al. Multimodal approach to screening for ovarian cancer. Lancet. 1988;1:268-271.

13. Jacobs I, Davies AP, Bridges J, et al. Prevalence screening for ovarian cancer in postmenopausal women by CA 125 measurement and ultrasonography. BMJ. 1993;306:1030-1034.

14. Adonakis GL, Paraskevaidis E, Tsiga S, Seferiadis K, Lolis DE. A com bined approach for the early detection of ovarian cancer in asymptomatic women. Eur J Obstet Gynecol Reprod Biol. 1996;65:221-225.

15. Bell R, Petticrew M, Luengo $S$, Sheldon TA. Screening for ovarian cancer: a systematic review. Health Technol Assess. 1998;2(2):i-iv, 1-84.

16. Vuento MH, Pirhonen JP, Makinen JI, Laippala PJ, Gronroos M, Salm TA. Evaluation of ovarian findings in asymptomatic postmenopausal women with color Doppler ultrasound. Cancer. 1995;76:1214-1218.

17. Kurjak A, Shalan $H$, Kupesic $S$, et al. An attempt to screen asymptomatic women for ovarian and endometrial cancer with transvaginal color and pulsed Doppler sonography. J Ultrasound Med. 1994;13:295-301.

18. Gohagan JK, Prorok PC, Hayes RB, Kramer BS. The Prostate, Lung, Colorectal and Ovarian (PLCO) Cancer Screening Trial of the National Cancer Institute: history, organization, and status. Control Clin Trials. 2000;21(6 Suppl):251S-272S.

19. Prorok PC, Andriole GL, Bresalier RS, et al. Design of the Prostate, Lung, Colorectal and Ovarian (PLCO) Cancer Screening Trial. Control Clin Trials. 2000;21(6 Suppl):2735-309S.

20. Jacobs IJ. European Randomized Trial of Ovarian Cancer Screening (Protocol). London: Wolfson Institute of Preventive Medicine, Department of Environmental and Preventive Medicine; 1995.

21. American Cancer Society. Can ovarian cancer be found early? Available at: http://www.cancer.org/docroot/CRI/content/CRI_2_4_3X_Can_ovarian_cancer_be_found_early_33.asp?sitearea. Accessed April 2, 2003.

22. American College of Obstetricians and Gynecologists. Committee Opinion No. 280. The role of the generalist obstetrician-gynecologist in the early detection of ovarian cancer. Gynecol Oncol. 2002;87:237-239.

23. Gladstone CQ. Screening for ovarian cancer. In: Canadian Task Force on the Periodic Health Examination. Canadian Guide to Clinical Preventive Health Care. Ottawa: Health Canada, 1994;870-881. 